\title{
Centrismo e híbrido político: o sentido da política
}

\author{
Centrism and political hybrid: the meaning of the politics
}

\section{Alysson HUBNER* Joel PAESE ${ }^{* *}$}

\begin{abstract}
Resumo: Os posicionamentos políticos têm gerado sentidos extremamente heterogêneos. As noções de direita, esquerda e centro são utilizadas para observar a posição política que os agentes possuem na sociedade. O objeto de estudo são os conceitos e as noções de centrismo e híbrido político, que permitem evidenciar as complexas associações políticas. Este artigo tem por objetivo observar, a partir da sociologia compreensiva de Max Weber, qual é a conexão de sentido que os docentes do campus Sapucaia do Sul, do Instituto Federal Sulrio-grandense, atribuem a determinada posição política, a fim de identificar como se percebem politicamente nestas categorias. A metodologia consistiu na aplicação de um questionário semiestruturado, com a criação de 6 tipificações políticas: direita, centro-direita, centro, centro-esquerda, esquerda e outro, dentre as quais os docentes escolheram sua posição. Uma segunda pergunta procurou compreender o que os docentes entendiam sobre estes posicionamentos, analisando, assim, seus significados. Os resultados apontam para uma ampla predominância da perspectiva vinculada ao posicionamento centro-esquerda, que corresponde a $43 \%$ dos docentes, seguidos respectivamente de esquerda $22 \%$, centro-direita $14 \%$, outro $14 \%$ e centro $7 \%$. Estes dados apontam para uma perspectiva diferente daquela atribuída pelo senso comum, que considera todas as instituições públicas de educação como de "esquerda". A noção de "centro", vinculada à esquerda, bem como a de direita, quando somadas - nos 3 posicionamentos - correspondem a $64 \%$. Assim, a noção de centrismo, conforme Norberto Bobbio, ou híbrido político, é mais adequada para compreender os posicionamentos políticos dos docentes, bem como outros modelos de Estado, conforme Hutton e Giddens, na qual as instituições públicas e privadas são observadas de maneira complexa.
\end{abstract}

Palavras-chave: Centrismo.Centro-esquerda. Centro. Centro-direita. Híbrido político.

Abstract: Political positions have generated extremely heterogeneous meanings. The notions of right, left and center have been used to observe the political position that agents have in society. The object of study are the concepts and notions of centrism and political hybrid, which allow to highlight the complex political associations. This article aims to observe, from the perspective of Max Weber's comprehensive sociology, what is the connection of meaning that the teachers of the Sapucaia do Sul campus, of the Federal Institute of Sul-riograndense, attribute to a certain political position, in order to identify how they perceive themselves politically in these categories. The methodology consisted in the application of a semi-structured questionnaire, with the creation of 6 political typifications: right, center-right, center, center-left, left and other, from which the teachers chose their position. A second question sought to understand how the teachers understood these positions, thus analyzing their meanings. The results point to a large predominance of the center-left position, corresponding to $43 \%$ of the teachers, followed respectively by left, $22 \%$, center-right $14 \%$, other $14 \%$ and center $7 \%$. These data point to a different perspective from that attributed by the common sense, which considers all pub-

\footnotetext{
* Cientista Político. Doutor em Sociologia pela Universidade Federal da Paraíba (UFPB). Professor do Instituto Federal Sul-rio-grandense (IFSUL, Sapucaia do Sul, Brasil). Avenida Copacabana, no 100 , Bairro Piratini, Sapucaia do Sul (RS), CEP.: 93216-120. E-mail: <alyssonhubner@yahoo.com.br>. ORC ID: $<$ https://orcid.org/oooo-0o01-6080-6530>.

${ }^{* *}$ Professor. Doutor em Sociologia Política pela Univ ersidade Federal de Santa Catarina (UFSC). Professor da Universidade Federal de Mato Grosso (UFMT, Cuiabá, Brasil). Av. Fernando Corrêa da Costa, $n^{\circ} 2367$, Bairro Boa Esperança. Cuiabá (MT), CEP.: 78060-90o. E-mail: <joelpaese@gmail.com>. ORC ID: <https://orcid.org/o000-0001-7309-3226>.
} 
lic educational institutions as "left". The notion of "center", linked to the left, as well as the right, when added - in the 3 positions - correspond to $64 \%$. Thus, the notion of centrism, according to Norberto Bobbio, or political hybrid, is more adequate to understand the political positions of the teachers, as well as other models of State, according to Hutton and Giddens, in which public and private institutions are observed in a complex way.

Keywords: Centrism. Center-left. Center. Center-right. Political hybrid.

Submetido em: 14/9/2017. Aceito em: 5/5/2018.

\section{INTRODUÇÃO}

$\mathrm{E}$ sta pesquisa procede, em parte, da articulação teórico-metodológica proposta por Bourdieu (2004), que consiste em construir as desconstruções das pré-noções. Estas podem ser observadas com a pré-noção de que as instituições de ensino públicas são de esquerda. Nosso estudo, por sua vez, contribui para essa desconstrução ao identificar que a esquerda corresponde ao posicionamento político de $21,4 \%$ dos que responderam o questionário na instituição de ensino público pesquisada, o que equivale a uma não correspondência com os juízos de senso comum a respeito do tema. A construção, por seu turno, corresponde ao fato de que o posicionamento político predominante se localiza na posição de centro-esquerda, que corresponde a $42 \%$ das respostas. Além disso, quando somadas as duas perspectivas - centro-esquerda e centro-direita - este percentual sobe para 56,3\%, e quando somadas as três perspectivas - centro-esquerda, centro e centro-direita - a taxa aumenta para $63,4 \%$, o que nos leva a sugerir as noções de centrismo e híbrido político.

A noção de híbrido adotada aqui se fundamenta em Latour (1994; 2008), e diz respeito à conexão entre natureza e sociedade, humanos e não humanos, e agências múltiplas. No caso da política, os agenciamentos ocorrem em termos de direita e esquerda política, o que implica a situação de centrismo, ou seja, centrismo pode ser observado como um híbrido político. Nessa perspectiva, no centro predomina a tentativa de combinar posicionamentos, a princípio distintos, ao invés de opô-los de modo a torná-los irreconciliáveis.

A primeira parte do texto procura apresentar os pressupostos das tipificações da sociologia compreensiva de Weber (2009), em que são abordadas determinadas categorias oferecidas como base inicial para compreender o sentido pelo qual os agentes pesquisados apreendem a política. A coleta dos dados, em consequência, se orienta por uma conexão indissociável entre teoria e metodologia.

A segunda parte, mais extensa, analisa os dados da pesquisa a partir da resposta dos docentes sobre seu posicionamento político, o que permitirá correlacioná-los com a noção de centrismo em Bobbio (1997), bem como sugerir a noção de híbrido político na explicação do posicionamento político observado. Trata-se da análise da autodeclaração dos respondentes quanto à sua posição política. Também estão presentes nessa seção os modelos de Estado que esses posicionamentos sugerem, conforme Hutton e Giddens (2004), em que as perspectivas de centro têm se tornado cada vez mais observadas nos estudos realizados sobre o tema ${ }^{1}$.

\section{COMPREENDENDO O SENTIDO DE POLÍTICA NA CONCEPÇÃO WEBERIANA}

1 Ver Rodrigues (2002).

Argum., Vitória, v. 10, n. 2, p. 174-189, maio/ago. 2018. 
Conforme Weber (2009), a Sociologia procura compreender o sentido subjetivo que os agentes atribuem à ação. Isso significa resgatar uma determinada subjetividade que é negligenciada pelas demais perspectivas da sociologia clássica, que correspondem ao materialismo histórico e ao funcionalismo.

Os tipos ideais são construções teóricas que servem como modelo analítico, a fim de correlacionar o quanto a observação se aproxima deste construto (WEBER, 2009). O modo pelo qual os tipos ideais foram criados, entretanto, não implica estabelecer um juízo de valor, atribuindo um sentido completamente dissonante das autopercepções dadas pelos respondentes. São propostos, então, 6 tipos ideais: direita, centro-direita, centro, centro-esquerda, esquerda e outro. Essas tipificações são complexas, podendo variar desde as concepções das funções do Estado, em que uma noção vinculada a um Estado mínimo ou a um Estado Liberal é associada à direita, enquanto um Estado que abrange mais funções, no sentido de desempenhar atribuições relativas à educação, saúde e transporte, por exemplo, é associado à esquerda. Mas existem também os valores relativos a estas tipificações, o que torna a questão ainda mais complexa, como no caso das questões vinculadas à sexualidade, que podem variar por completo, conforme uma esquerda suscetível de ir ao encontro destas causas ou mesmo de ir de encontro a elas. Com o objetivo de minimizar tais dificuldades, parte-se da autopercepção fornecida pelos docentes que responderam o questioná rio.

\section{OS DOCENTES E O SENTIDO DA POLÍTICA NAS NOÇÕES DE CENTRISMO E HÍ- BRIDO POLÍTICO}

Foram disponibilizados questionários a 28 docentes, de um total de 78 professores vinculados ao campus, ou que nele ministram aula. Com relação à amostra e aos fatores éticos da pesquisa, o procedimento foi o seguinte: o questionário foi remetido pelo e-mail institucional oficial do Instituto Federal Sul-rio-grandense, que constitui uma ferramenta de trabalho obrigatória para o exercício da atividade docente. Assim, a priori, todos os docentes receberam o e-mail. A não devolução dos formulários com respostas pelos professores aos quais foram remetidos se deve a diversos motivos, que fogem à alçada dos pesquisadores.

Sabe-se, diga-se de passagem, que este procedimento de pesquisa está sujeito a uma taxa baixa de retorno. Cabe salientar aqui alguns dos casos, como daqueles docentes oficialmente vinculados ao campus, mas em exercício de cooperação técnica, o que significa que estão cedidos para outra instituição pública, existindo, também, casos de docentes residindo em outros Estados brasileiros. Outras situações se referem a afastamentos por motivos de doença grave. O questionário ficou disponibilizado para resposta por cerca de um mês. Mais de um e-mail foi enviado, inclusive contendo o compromisso ético que envolve a presente pesquisa científica - consubstanciado no termo de consentimento livre e esclarecido - , assegurando o resguardado do anonimato dos professores, sem que haja prejuízo para os participantes da pesquisa. O procedimento visou à participação dos docentes, à segurança nas respostas e a evidenciar a responsabilidade ética com a qual os pesquisadores estão comprometidos na investigação em tela. Além desse instrumento, as relações face a face e virtuais, como o WhatsApp, também foram utilizadas para informar os objetivos, a abrangência e os métodos da pesquisa, o que contribuiu para maior engajamento e participação dos docentes. 
Dentre os que responderam ao questionário, 9 possuem graduação em Engenharia ${ }^{2}, 6$ são das Ciências Humanas ${ }^{3}, 4$ das Ciências Exatas ${ }^{4}, 2$ de Linguagens ${ }^{5}, 2$ das Ciências da Saúde ${ }^{6}, 2$ tecnólogos e 3 não informaram. No tocante aos atributos de escolaridade, a distribuição é a seguinte:

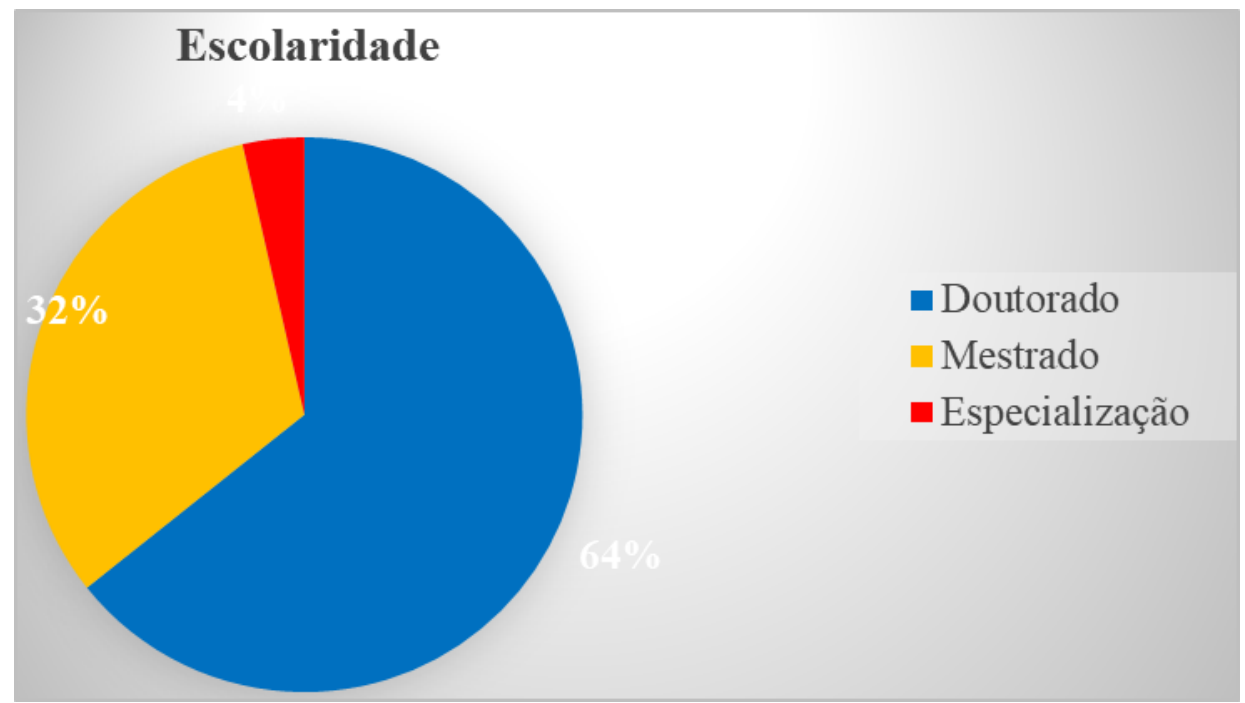

Gráfico 1: Escolaridade dos respondentes Fonte: Elaborado durante a pesquisa de campo.

Quanto à escolaridade, 18 possuem doutorado, o que equivale a 64\%; 9 possuem mestrado, o que corresponde a 32\%; e 1 possui especialização, equivalente a $4 \%$.

No que se refere ao $\operatorname{sexo}^{7}$, os respondentes estão assim distribuídos:

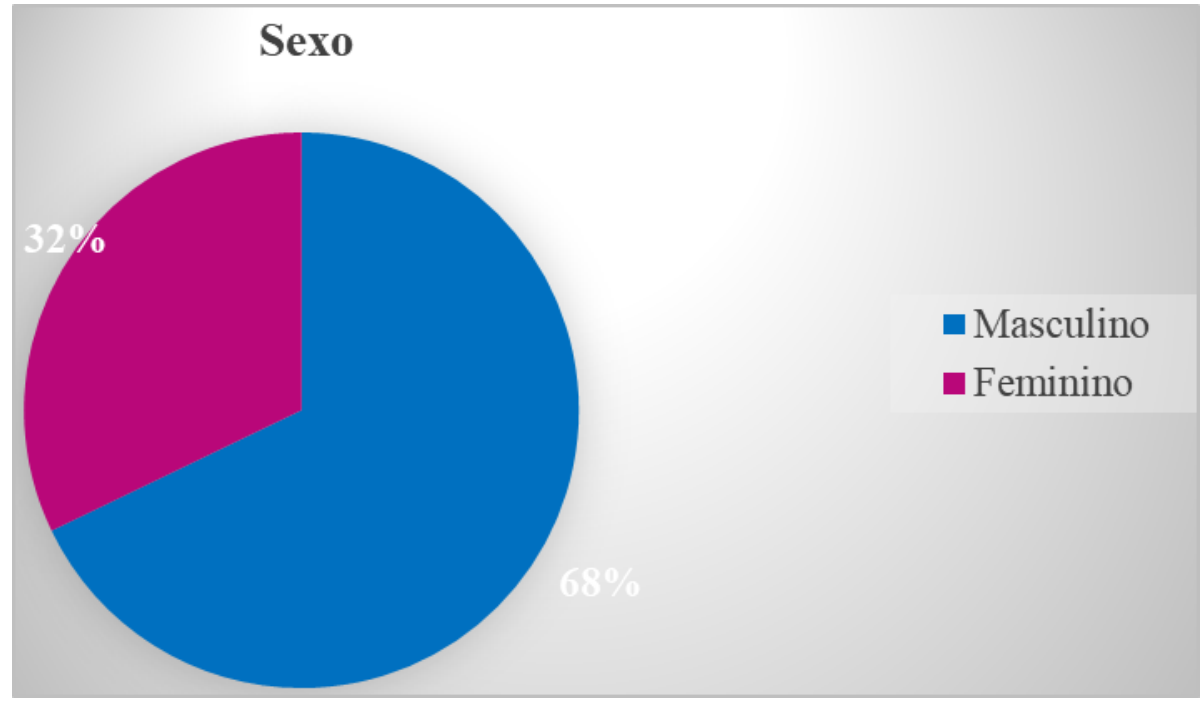

Gráfico 2: Sexo dos respondentes.

Fonte: Elaborado durante a pesquisa de campo.

2 Em Mecânica 7, em Computação 1 e em Química 1.

3 Das Ciências Sociais 2, da Filosofia 1, da Pedagogia 1, da Economia 1e da Administração 1.

4 Da Física 2, da Matemática 1 e das Ciências Contábeis 1.

5 Em Letras 2.

6 Em Educação Física 1 e em Biologia 1.

7 Cabe salientar que a variável sexo não é uma categoria central de análise na pesquisa, mas complementar . Assim, o seu aprofundamento não pertence aos objetivos centrais definidos no escopo do artigo, levando tal digressão à fuga do objeto.

Argum., Vitória, v. 10, n. 2, p. 174-189, maio/ago. 2018. 
A amostra está assim distribuída, pois diz respeito aos indivíduos que se dispuseram a responder o questionário: 19 docentes são do sexo masculino, o que equivale a $68 \%$ da amostra, e 9 deles são do sexo feminino, equivalente a 32\% da distribuição amostral da pesquisa. Esses professores atuam em diferentes cursos no campus de Sapucaia do Sul (RS): graduação em Engenharia Mecânica, Ensino Médio Técnico Integrado (Informática, Eventos e Plástico) e Proeja ${ }^{8}$ (Administração).

Foram formuladas duas perguntas a fim de identificar a autoclassificação política dos docentes. Uma que consistia na seguinte questão: Como você se percebe na perspectiva política? Foram apresentadas 6 opções de respostas, conforme já mencionado: direita, centro-direita, centro, centro-esquerda esquerda e outra. Vejamos o gráfico a respeito:

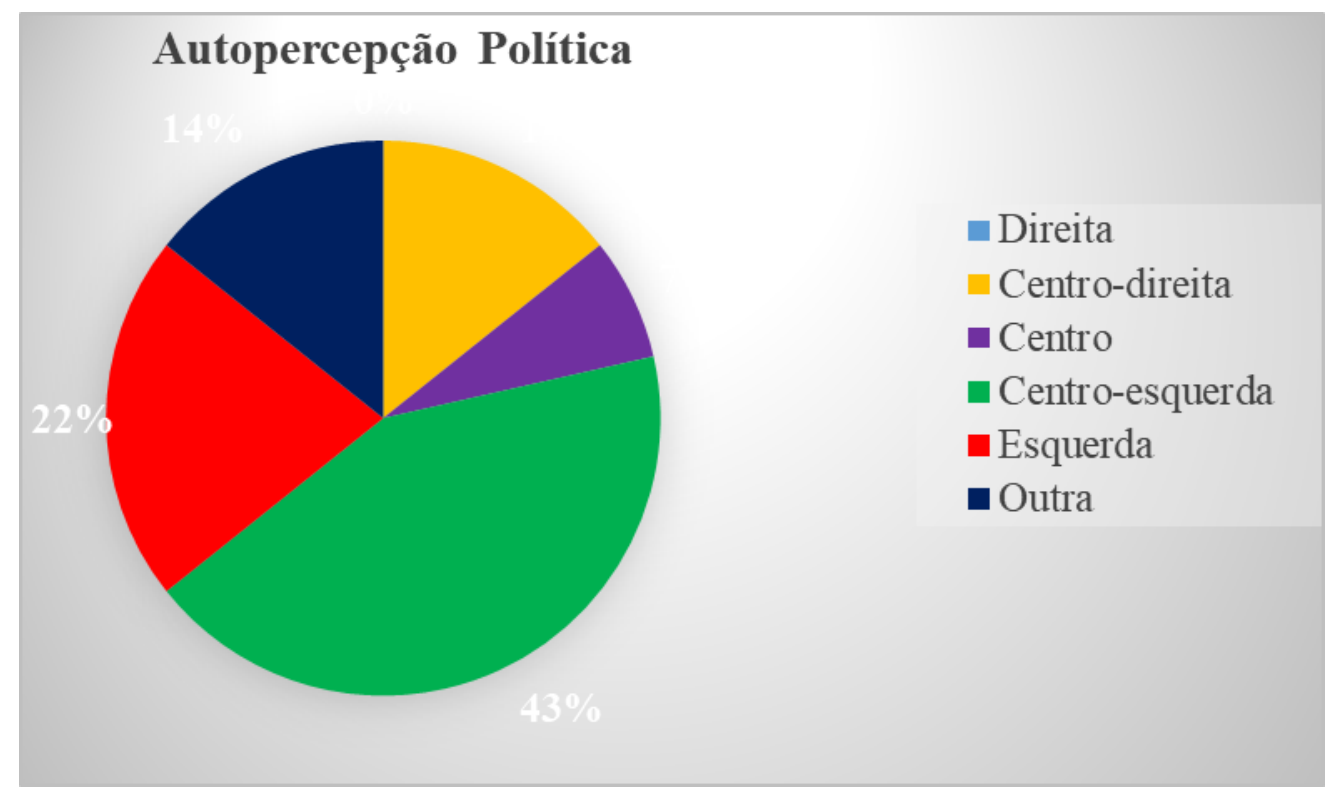

Gráfico 3: Autopercepção política dos respondentes.

Fonte: Elaborado durante a pesquisa de campo.

O maior grupo se percebe como de centro-esquerda, o que corresponde a $43 \%$ dos que responderam ao questionário, somando um total de 12 professores. O segundo maior grupo se autodenomina de esquerda, equivalendo a $22 \%$, em um universo de 6 pessoas. $\mathrm{O}$ terceiro grupo é dividido em dois subgrupos de idêntico percentual, $14 \%$, sendo que um deles se percebe como de centro-direita e os demais como outra. Já o menor grupo se considera de centro, totalizando 2 professores, o que corresponde a $7 \%$ dos respondentes. Nenhum respondente se autodeclarou como de direita. A primeira inferência que podemos fazer afirma a heterogeneidade da perspectiva política dos docentes que atuam no campus em foco.

A distinção entre a primeira dicotomia é válida para compreender a construção da identidade política dos docentes. Segundo Tarouco e Madeira (2013, p. 149),“a presumida distinção conceitual entre esquerda e direita continua sendo confrontada com escolhas e percepções dos eleitores para avaliar seu grau de identificação política”. Essa identificação política é da- 
da, em um primeiro momento, em relação ao sentido para o qual convergem os tipos propostos e elencados na pesquisa.

Foi questionado, em seguida, o significado deste posicionamento, com a seguinte pergunta: O que é esta posição para você? Podemos identificar, desse modo, os significados subjacentes a essas posições, que podem ser variáveis ou não. Assim, a seguir, analisaremos quais são as percepções atribuídas aos posicionamentos escolhidos.

\subsection{Centro-esquerda}

\section{2}

A posição centro-esquerda remete à emergência do Estado de Bem-Estar Social a partir da crise de 29 (PRZEWORSKI, 1995). Isso levou à emergência de novas formações políticas pelo mundo, dentre as quais podemos citar blocos políticos de direita negociando com a esquerda e vice-e-versa, constituindo novos arranjos institucionais suscetíveis de dar base à promoção de alianças cada vez mais amplas na sociedade.

[...] o conteúdo das categorias de esquerda e direita mudou consideravelmente ao longo do tempo. Entretanto, o significado que vincula a defesa da igualdade social, herdeira de princípios socialistas, com a esquerda, e a defesa do livre mercado capitalista com a direita parece ter sobrevivido aos rearranjos mundiais do final do século XX (TAROUCO; MADEIRA, 2013, p. 151).

Essas novas configurações políticas migraram para o contexto brasileiro, e estão, de alguma maneira, formalizadas na Constituição da República Federativa do Brasil de 1988, em que vários elementos deste modelo de Estado social-democrata são inscritos. A crise de um modelo - que entrou em colapso em 1929 - associado ao que é denominado direita, permite compreender o deslocamento de um novo arranjo institucional político rumo ao centro. $\mathrm{O}$ mesmo ocorre com as dificuldades enfrentadas após a década de 1970. A partir daí, o liberalismo reemerge após sua crise no final da década de 1920. Ao mesmo tempo, passa a sofrer a pressão de narrativas de esquerda, que o põem em xeque em vista da crise financeira de 2008.

Quanto aos docentes, o maior grupo, constituído pelos denominados e autodenominados de centro-esquerda, apresenta uma constituição heterogênea. Cabe salientar o que significa essa posição. Podemos identificar uma espécie de híbrido nesse posicionamento. Nele, os respondentes atribuem certas funções ao Estado, como educação e saúde, por exemplo. Estas são consideradas obrigações inalienáveis a serem cumpridas pelo aparelho estatal. Há coexistência desses deveres, entretanto, com o funcionamento do mercado segundo o liberalismo, estruturado pelas ações da próprias da iniciativa privada, não é descartada pelos respondentes, o que confere uma limitação à atuação do Estado. Estes professores são deslocados, assim, a uma posição mais ao centro, próxima aos princípios que podemos considerar liberais. É possível dividir esse grupo em dois subgrupos:

i. Centro-esquerda homogênea;

ii. Centro-esquerda heterogênea. 
O primeiro é mais extenso. Nele predomina uma combinação de diferentes elementos, sempre remetendo às duas perspectivas em coexistência. Conforme estes professores, ser de centro-esquerda significa:

i. $\quad$ Equilíbrio e busca por enxergar sempre os dois lados da "moeda";

ii. Simpatizo com a esquerda, mas não demonizo a direita;

iii. Acredito que deve existir um setor público robusto, mas que para isso também deve-se ter um setor privado forte;

iv. Aceitar o capitalismo desde que existam medidas disponíveis a todas as pessoas para obterem sucesso no sistema independente de sua classe social;

v. Acredito que é uma posição coerente com a classe trabalhadora e com a estabilidade econômica do Brasil;

vi. Tanto a direta quanto a esquerda são radicais demais. Portanto tenho maior simpatia pelas políticas esquerdistas (centro-esquerda) que visam igualar um pouco mais as condições de vida das pessoas;

vii. Acredito que o estado deve ter um peso grande mas deve estimular a iniciativa privada.

Do total de 12 pessoas inseridas nessa perspectiva, 7 fazem referências explícitas ao hibridismo que caracteriza esse posicionamento político, conforme pode ser observado acima. A noção de centrismo é adequada para compreender esse movimento político híbrido. Conforme Bobbio (1997),"Centrismo deriva claramente de centro. Em linhas gerais, o centro, segundo a visão geométrica tradicional da política, que se baseia na dicotomia 'mudançaconservação', é a posição intermédia por excelência” (BOBBIO, 1997, p. 158). Isso implica que o equilíbrio almejado pela perspectiva de centro está mais próximo de uma combinação de domínios que, em seu devir, podem se revelar não antagônicas. Parte dos motivos indicados pelos que responderam o questionário também se coaduna com aquilo que o centrismo promove.

As motivações que determinam o Centrismo pressupõem todas elas a dificuldade da escolha; todavia, podem ser assim esquematizadas: escolhe-se o Centrismo, ou porque se crê que ambas as posições opostas apresentam elementos positivos tais que justifiquem uma síntese ou mediação, ou porque se considera que ambos os contendores estão errados; então a via justa em situar-se ao centro, isto é, acima das facções (BOBBIO, 1997, p. 158).

O docente 6 corrobora a segunda parte da motivação indicada, ao afirmar que esquerda e direita são radicais demais, associando predicados negativos às posições dicotômicas. Já os respondentes $2,3,5$ e 7 se referem à primeira motivação do centrismo, pois identificam predicados positivos em doutrinas políticas de esquerda e de direita.

O segundo subgrupo, por sua vez, é constituído de 5 professores, caracterizado por uma maior heterogeneidade. Essas 5 pessoas fazem referências diferentes. Uma, por possuir experiência em instituição com pessoas que denomina de extremistas, revisou sua posição política. Uma segunda professora afirma que o extremismo de esquerda lhe afasta deste posicionamento, remetendo-a ao centro, mas não menciona o que seria esse centro. Uma terceira afirma estar um pouco perdida na atual conjuntura política, levando-a a uma espécie de res-

Argum., Vitória, v. 10, n. 2, p. 174-189, maio/ago. 2018. 
significação do seu posicionamento. A quarta remete somente a aspectos das funções de Estado. Já o quinto faz referência somente a aspectos progressistas, em termos ideológicos.

Essas situações políticas são observadas não apenas no contexto brasileiro, conforme mostra Marti Puig (2013). Segundo o autor, está em marcha um “[...] proceso de conversión y consolidación del sistema político nicaragüense en un régimen híbrido” (PUIG, 2013, p. 1). São contextos alhures nos quais pode-se observar o hibridismo político em um processo de constante transformação e negociação, consolidado em alianças políticas. No início deste século, a perspectiva de centro-esquerda predominou no contexto europeu.

É irônico que hoje governos de centro-esquerda estejam ao mesmo tempo no poder em todas as principais nações europeias, pela primeira vez na história - Londres, Paris, Roma e Berlim. Dos quinze países da União Européia (sic), nada menos que treze são governados por partidos de esquerda democrática (HUTTON; GIDDENS, 2004, p. 266).

O predomínio da perspectiva de centro-esquerda no final dos anos de 1990 e início do século XXI - conforme o contexto histórico dessa citação - se manifesta como hegemonia político-econômica em constante expansão, que, por sua vez, passa a se perpetuar de maneira extensiva, em vista da sociedade globalizada.

O 'livre' comércio como elemento antagônico da 'regulamentação’ do Estado é um paradoxo que a perspectiva centro-esquerda procura observar, pois: 'O sistema financeiro tem de ser regulamentado, paradoxalmente, para proteger o livre comércio. O controle dos capitais é essencial para manter aberto o mercado de bens e serviços' (HUTTON; GIDDENS, 2004, p. 306).

As noções de livre e regulamentado estão em situações de justaposição, que permitem a formação de um híbrido político e econômico. Trata-se de um paradoxo que torna problemática a pretensão da modernidade de dividir a realidade em sistemas compartimentados e especializados. Em jogo, está a possibilidade de explicações multidimensionais e complexas, nos termos da episteme moderna (GIDDENS, 1991). Deste modo, a política de centro sugere uma crítica ao princípio de classificação moderno, em favor de uma perspectiva diferente, que se robustece a partir da segunda metade do século XX.

Assim se apresenta, por sua vez, o outro fator que estrutura a crítica ao liberalismo, coadunado com a perspectiva de centro-esquerda: "É preciso acabar com os paraísos fiscais, financeiros e empresariais; são formas importantíssimas de evasão tributária e berço de imensos reservatórios de capital especulativo" (HUTTON; GIDDENS, 2004, p. 309). A crítica ao mercado especulativo, associado a crises no Estado de bem-estar social, pode ser observada na perspectiva política de centro-esquerda. Estas supostas irracionalidades dos mecanismos de mercado seriam corrigidas a partir da atuação do Estado.

Assim, no grupo de centro-esquerda prevalece o hibridismo político como característica, embora seja formado por dois subgrupos, no qual o primeiro e maior grupo é mais coeso. A autopercepção política deste agrupamento se estrutura a partir da possibilidade de coexi stência de duas perspectivas em aparente contradição, ao passo que o segundo é mais fragmentado quanto aos motivos que orientam os posicionamentos de centro-esquerda.

Argum., Vitória, v. 10, n. 2, p. 174-189, maio/ago. 2018. 


\subsection{Esquerda}

O segundo maior grupo é formado pelos professores que se percebem como de esquerda. Este posicionamento político é associado, conforme os docentes, a uma visão em que o Estado se expande para ampliar o número de funções sob sua responsabilidade, estendendo sempre mais sua intervenção na sociedade, seja no âmbito macrossocial ou microssocial. Inexiste referência ao setor privado. É um grupo mais homogêneo em termos de coesão interna quanto aos seus princípios orientadores, com pequenas variações. Podemos observar tais aspectos nas seguintes respostas:

i. Defender a propriedade pública dos meios de produção, que o Estado esteja a serviço das pessoas com menor renda, incluindo no controle sobre à produção. Defender a reforma agrária, urbana e financeira, dentre outras coisas;

ii. Uma posição que busca maior igualdade social, através de políticas que sejam focadas nas camadas historicamente menos favorecidas da população;

iii. Representa a minha visão de que o estado tem função primordial nas áreas como educação, saúde e infraestrutura. Sendo o estado a força motriz para o desenvolvimento de uma nação mais soberana e independente;

iv. Esquerda representa uma posição a favor de igualdades sociais, respeito à cidadania, e contrária a autoritarismos;

v. Lutar por justiça social e equidade com sustentabilidade;

vi. Essa posição para mim está relacionada a uma perspectiva de valorização da vida humana e de suas necessidades. Compreendo que os indivíduos, deixados livremente em busca de seus interesses, não garante condições mínimas de vida para o conjunto da população. Destacaria, entre essas dimensões, o direito à moradia, comida, educação, liberdade de expressão e religiosidade, livre associação, lazer, trabalho livre e justamente remunerado e proteção contra violência e abusos de poder.

A noção de controle do Estado extraída da resposta do docente 1 deste grupo, sintetiza os elementos contidos nas demais respostas. Estas associam a igualdade social, conforme o segundo professor, com a função do Estado como força motriz de acordo com o terceiro docente, com o respeito a cidadania em conformidade com a quarta resposta, com a noção de sustentabilidade formulada pelo quinto professor, bem como com a crítica ao modelo liberal de desenvolvimento, segundo o sexto docente. A única noção que destoa do modelo é a de sustentabilidade, uma vez que procura combinar diferentes modelos de desenvolvimento. Devido, entretanto, às múltiplas noções de sustentabilidade formuladas, era importante propor uma questão sobre o que é sustentabilidade para os respondentes, questão que não foi possível de ser realizada, ficando esta lacuna a ser preenchida em outro momento.

Argum., Vitória, v. 10, n. 2, p. 174-189, maio/ago. 2018. 
Embora exista uma relativa heterogeneidade com relação aos elementos vinculados à esquerda nos seus posicionamentos ${ }^{9}$, a homogeneidade prevalece quando está em jogo a função do Estado de constituir o núcleo normativo da sociedade, bem como a restrição ao setor privado enquanto o elemento propulsor do desenvolvimento social. Também a noção de igualdade é central nessa perspectiva, o que sugere a existência de uma determinada identidade política peculiar, sendo essa noção um fundamento de coesão interna do grupo em tela. Em uma pesquisa realizada sobre a representatividade política no Congresso Nacional no ano de 2002, Rodrigues (2002) demonstra que os representantes políticos quando provenientes da profissão professor tendem a se situar mais à esquerda. Também são encontrados, entretanto, docentes nos outros posicionamentos políticos que não da esquerda, embora seja em menor número (RODRIGUES, 2002).

Existe a possibilidade de observar o predomínio da perspectiva de esquerda na posição dos docentes, quando se soma esquerda e centro-esquerda, com um percentual correspondente a $65 \%$. Ainda assim, a soma das perspectivas de centro precisa ser desagregada em 3 posicionamentos: centro-esquerda, centro e centro-direita, o que equivale aos $64 \%$ referidos acima. Importa observar que a percepção de senso comum sobre as instituições públicas de ensino não é destituída de verdade, em certa medida, quando afirma que essas são de esquerda, como os próprios dados evidenciam. Negligenciar, porém, o papel do centro nessa configuração significa não adentrar na complexidade que envolve as interações políticas.

Deve-se considerar a importância da questão do proletariado para a esquerda. Conforme Tarouco e Madeira (2003, p. 150),"[...] com a expansão do movimento operário e a difusão da perspectiva marxista o conteúdo da posição de esquerda passa a incorporar a defesa dos interesses da classe proletária” (TAROUCO; MADEIRA, 2003, p. 150). Trata-se de defesa clara e aberta do posicionamento político de esquerda.

Embora a questão do centrismo não tenha sido contemplada na percepção desse grupo sob a forma do hibridismo político — , a conotação atribuída ao centrismo pelas posições alinhadas tanto à esquerda quanto à direita pode ser sintetizada, em parte, na seguinte observação: “[...] para os opositores [...] Centrismo é sinônimo de indecisão, imobilismo, de oportunismo, etc." (BOBBIO, 1997, p. 158). As perspectivas mais alinhadas ao que se denomina de "prática política" - sob a feição, muitas vezes, do ativismo — identificam uma inação no tocante às possibilidades de alianças políticas, ou mesmo de incorporação de elementos externos em sua visão sistemática da política.

\subsection{Centro-direita}

As concepções da posição política denominada e autodenominada de centro-direita compreendem o terceiro maior grupo dos docentes. No que se refere à perspectiva de centro, o termo sugere uma aproximação ao maior grupo dos professores, os denominados centroesquerda. Pode existir, entretanto, uma inversão na noção de centro, tanto para a esquerda como para a direita. Centro para a esquerda pode significar instituições privadas, enquanto

\footnotetext{
9 Heterogeneidade, no sentido de que existem elementos vinculados à noção de sustentabilidade e de cidadania citados, que podem ser variados, e que não puderam ser observados na presente análise em vista do recorte e limitações da pesquisa.
}

Argum., Vitória, v. 10, n. 2, p. 174-189, maio/ago. 2018. 
para a direita pode significar Estado. O grupo que se autoclassifica, no entanto, como de centro-direita, expressa diferentes significados para esse posicionamento político.

Podemos verificar nas respostas dos docentes desse grupo as seguintes conotações:

i. $\quad$ Liberdade de expressão;

ii. Conservador no que se refere a valores e tradições, liberal porém não libertário no campo econômico, defensor de uma presença estatal forte apenas em saúde, educação e segurança;

iii. Alguém que acha que o estado deve se preocupar, principalmente, com a educação, saúde e segurança. Procurando intervir menos na economia;

iv. É uma posição buscando ser realista e contrário ao governo dos últimos 10 anos.

Liberdade de expressão, conservadorismo, Estado social-democrata e crítica ao governo em relação aos últimos 10 anos são fatores que levam esse grupo a se auto classificar como centro-direita. Conjuntamente com o grupo outro, é o mais heterogêneo na perspectiva dos posicionamentos políticos.

A resposta do primeiro docente aponta para uma síntese do que vem a ser o núcleo estruturante do liberalismo. Segundo Dortier (2010), “Liberalismo' é um termo genérico que designa diferentes correntes e doutrinas forjadas no Ocidente no decorrer dos séculos a pa rtir da palavra-mestra "liberdade"' (DORTIER, 2010, p. 360). A complexidade que envolve a palavra liberdade, assim como a influência que adquire na sociedade, permite que migre para diferentes concepções políticas. A direita, porém, ainda procura resguardá-la como um valor, no intuito de estruturar uma determinada identidade política específica.

As respostas dos docentes 2 e 3 permitem uma maior aproximação ao subgrupo de centroesquerda mais homogêneo ${ }^{10}$, uma vez que também apontam para duas esferas de visões distintas, mas em coexistência não-antagônica. É importante salientar que as perspectivas de centro sugerem uma oposição à noção de antagonismo, pois a subsistência de uma relação não conflituosa se apresenta como factível em seu horizonte de eventos. As perspectivas do hibridismo e do antagonismo, portanto, sustentam posicionamentos políticos distintos - o centrismo e as posições que transitam rumo aos extremos, respectivamente. Conforme o ideal centrista aplicado ao papel do Estado na economia, pode-se afirmar que

O mais centrista dos ideólogos empresariais concordaria que o estado deve ainda ter um papel residual para subsidiar a educação e o treinamento dos trabalhadores, atenuar desorganizações periódicas, financiar a pesquisa pré-competitiva e fornecer formas (reduzidas) de renda social (HUTTON; GIDDENS, 2004, p. 216).

Este sentido compreende uma situação na qual o capitalismo desempenha um papel importante no desenvolvimento da sociedade, que pode contribuir, por exemplo para sua maior organicidade. Para a sua sustentação, entretanto, as funções do Estado passam a ser desdobradas em ações na área de educação, não se constituindo como funções antagônicas ao de-

10 Descrito no ponto 2.1 Centro-esquerda.

Argum., Vitória, v. 10, n. 2, p. 174-189, maio/ago. 2018. 
senvolvimento da sociedade. Assim, a educação, como função do Estado, é condição sine qua non para a manutenção do sistema capitalista, e não o contrário.

\subsection{Outro e Centro}

Entender o centrismo é um desafio, caracterizado por pares de oposição que levam à complexificação do pensar a respeito de um híbrido político. Capitalismo e socialismo, nesse sentido, estão justapostos em um modelo de centro que abre a possibilidade de intercomunicação entre opostos.

O colapso do socialismo real no leste europeu, a crise fiscal do welfare-state e a consequente proliferação do neoliberalismo, a revisão operada pelos partidos socialdemocratas no sentido da chamada terceira via, a onda das chamadas reformas de segunda geração (posteriormente ao Consenso de Washington), tudo isso parece ter aproximado do centro tanto a esquerda quanto a direita, mas não lhes subtraiu o sentido geral que coloca a luta pelo socialismo e a defesa do capitalismo em extremos opostos do mesmo gradiente (TAROUCO; MADEIRA, 2013, p. 151).

A conjuntura político-econômica é um fator que pode fazer emergir na sociedade, em momentos específicos, críticas recíprocas entre as diferentes perspectivas políticas. Ao mesmo tempo, o liberalismo - após a crise de 1929 - , bem como o modelo do welfare-state, baseado em um Estado ampliado excessivamente - a partir do final dos anos de 1970 - passaram a ser suscetíveis a mútuas restrições. A percepção de suas limitações e de suas possibilidades, por sua vez, pode ensejar a emergência do centrismo.

A perspectiva outro corresponde a $14 \%$ das respostas e não se observa elementos em comum entre elas, conforme abaixo:

i. Me considero anarquista. Mas meu anarquismo é um anarquismo filosófico-pragmático. Não acredito que um dia a sociedade será anarquista, nem acredito que as pessoas seriam verdadeiramente livres e emancipadas se assim fosse. Acredito em um anarquismo que vou construindo no dia a dia, em minhas próprias práticas e nas interações que entabulo com os agentes com que convivo;

ii. Um projeto de sociedade em disputa com os demais, diante da impossibilidade de conciliação entre eles, já que seus pressupostos e objetivos são antagônicos;

iii. Sem resposta;

iv. Não tenho definição política.

Pode ser considerado o grupo mais heterogêneo de todos, sendo que a primeira resposta diz respeito a uma posição que se pode classificar como anarquista, com uma série de explicações e conexões. Há, na segunda resposta, um retorno à proposição de antagonismo, que remete a uma posição que se coaduna ao grupo esquerda, descrito anteriormente. O terceiro e o quarto respondente, respectivamente, expressam uma ausência, tanto de resposta como de autodefinição política. Sob este aspecto é possível relacionar a resposta 3 da perspectiva outro com a resposta 2 da perspectiva Centro (7,1\% do total), conforme pode ser observado nas duas respostas centro, que são as seguintes: 
i. Não sou nem direita nem esquerda. Sou a favor que é melhor para o meu país, seja do governo de direita ou esquerda. Aliás, o PT era de esquerda e quando foi governo fez muitas coisas de direita;

ii. Neutra.

Assim, é mais provável encontrar uma conexão maior entre um membro do grupo centro e um membro do grupo outro, do que entre os próprios membros de cada grupo. Já a resposta 1 do grupo centro demonstra o que podemos denominar de transformação política no período das eleições e no período de efetiva governabilidade, nos seguintes termos: "Quando o grau de polarização das partes que se defrontam se eleva a ponto de pôr em grave perigo a mútua existência física, é então que nascem os agrupamentos, as coalizões, os partidos de centro, as atitudes e políticas centristas [...]" (BOBBIO, 1997, p. 158).

O centro, nesse caso, pode ser considerado um princípio de não violência física, ao passo que o Estado se caracteriza pelo monopólio do uso legitimo da violência física. Tal paradoxo é aparente, já que está instituído na essência da especificidade do poder político estatal.

É possível, também, estabelecer determinada conexão entre centrismo e cidadania. Conforme Marshall (1967), a cidadania é um conjunto de direitos adquiridos no decorrer dos séculos XVII, XVIII e XIX - civis, políticos e sociais, respectivamente. A concepção centrista pode estar contida nessa perspectiva, pois compreende que os direitos civis estão vinculados à liberdade em um sentido mais amplo, a uma desautorização da prática do Estado de intervir nas liberdades individuais. Essa restrição também diz respeito à liberdade das instituições privadas, abarcada por esse princípio específico da cidadania - além de outros direitos de grupos diferentes. Os direitos sociais, por seu turno, estão associados à atuação do Estado saúde, educação, etc. - , em que esse agente institucional passa a intervir na sociedade no intuito de executar essas funções. Instaura-se o que podemos chamar de paradoxo da cidadania. Este consiste em autorizar a intervenção do Estado na sociedade, a partir das demandas geradas pelos direitos sociais, ao mesmo tempo em que a autorização é restringida, em função dos direitos individuais. Assim, a tensão entre autorizar e desautorizar pelo Estado se converte uma condição paradoxal da realização da cidadania - a tentativa de conciliar os contrários - alinhado à concepção centrista.

\section{CORRESPONDÊNCIA ENTRE VOTO PARA PRESIDENTE DA REPÚBLICA E IDENTIFI- CAÇÃO POLÍTICA CENTRISTA}

A correlação que a pesquisa permite observar entre os posicionamentos políticos dos docentes e seu voto para presidente da república nas últimas eleições ${ }^{11}$ permite afirmar que há uma coerência em termos de identificação política e votação, uma vez que $61 \%$ dos respondentes votaram na candidata Dilma.

Quando questionados sobre em qual candidato à Presidência votaram, os números relativos são os seguintes:

11 Eleições presidenciais de 2014 no Brasil.

Argum., Vitória, v. 10, n. 2, p. 174-189, maio/ago. 2018. 


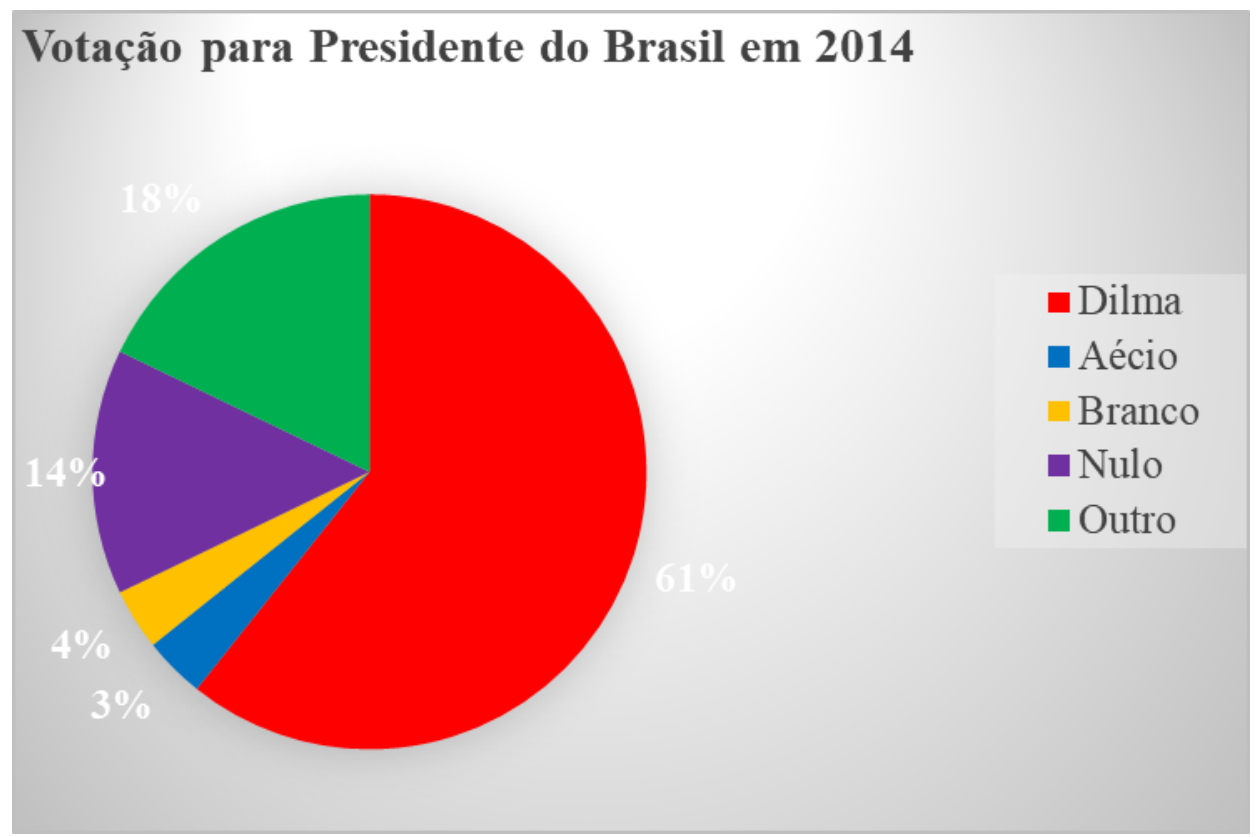

Gráfico 4: Votação dos respondentes na eleição para Presidente do Brasil em 2014 Fonte: Elaborado durante a pesquisa de campo.

Se notarmos que a soma dos percentuais referentes aos posicionamentos políticos - centrodireita, centro e centro-esquerda - é 64\%, podemos identificar elevado grau de correspondência com a votação na candidata Dilma. Não significa, porém, que todos que se posicionaram de algum modo no centro, em uma de suas variantes, tenham votado nesta candidata. Mostra, no entanto, que há correlação significativa entre percepção política e prática política quanto ao sufrágio universal. Conforme estudos sobre o significado dos partidos situados na direita e esquerda, pode-se afirmar que

A disposição do PT e do PDT na esquerda, PMDB e PSDB no centro, e PDS, PPR, PPB, PP, PTB e PFL/DEM na direita, que costuma ser admitida em estudos de diversas áreas, pode ser verificada nas classificações adotadas por vários autores que se dedicaram ao estudo dos partidos brasileiros (TAROUCO; MADEIRA, 2013, p. 150).

Isso é conexo com o voto da maior parte dos docentes, que escolheram a candidata Dilma representante da coligação PT e PMDB. Quanto aos dados referentes à votação no Brasil, verificamos os seguintes resultados, de acordo com o TSE ${ }^{12}$ : "[...] a chapa composta por Dilma Rousseff e Michel Temer recebeu 54.501.118 votos - 51,64\% dos votos válidos - e a chapa integrada por Aécio Neves e Aloysio Nunes Ferreira obteve 51.041.155 votos - 48,36\% dos votos válidos" (TRIBUNAL SUPERIOR ELEITORAL, 2014). Deste modo, a diferença entre o percentual de votos na candidata Dilma pelos respondentes - $61 \%$ deles - e o percentual de votos nesta candidata pelos eleitores em geral - 51,64\% deles - é de 9,36 pontos percentuais. Significa que a diferença entre o resultado das urnas em todo o Brasil e dados sobre a votação dos professores que responderam o questionário é de menos de 10 pontos percentuais. Isso equivale a dizer que existe uma correspondência relativamente forte entre o senso comum ou sociedade civil e os docentes, pois corresponde a uma diferença de $15,34 \%{ }^{13}$, em

\footnotetext{
12 Tribunal Superior Eleitoral.

13 Valor correspondente à diferença de 9,36 pontos percentuais em relação aos $61 \%$ de votos dos docentes na candidata Dilma.
}

Argum., Vitória, v. 10, n. 2, p. 174-189, maio/ago. 2018. 
relação aos $61 \%$ encontrados no voto dos docentes, como indicado. Observa-se, assim, a presença de um híbrido político como fator estruturante da votação na coligação PT e PMDB nas últimas eleições presidenciais.

\section{CONSIDERAÇÕES FINAIS}

Os resultados da observação dos diferentes sentidos dados à política, na construção de uma determinada identidade política, são heterogêneos. Isso não significa que a sistematização não se torne possível, pois nomear e categorizar é uma necessidade para poder analisar o processo político. Essa questão foi instrumentalizada em nossa pesquisa a partir da metodologia dos tipos ideais propostos por Weber, e, posteriormente, consubstanciados nos 5 tipos ideais utilizados no questionário: direita, centro-direita, centro, centro-esquerda e outro.

A inexistência dos verbetes direita e esquerda no próprio dicionário de política de Bobbio (1997), e outras referências, demonstra uma dificuldade em compreender o seu sentido. Quando a noção de centro é procurada, entretanto, ela está presente. A presença ou ausência de uma determinada conceituação é muito relevante. Isso não significa que as noções de direita e esquerda não existam, pois elas possuem diferentes sentidos. Por isso, a ocorrência da noção de centrismo merece ser investigada.

As noções de centro, centrismo e hibridismo podem contribuir para identificar um movimento político paradoxal. A coexistência de uma potencial inação e ação política. A inação ocorre quando se cristaliza a percepção de que uma ação política prática não surtirá efeito, dados os obstáculos desencadeados pelos antagonismos renitentes. A tomada de decisão, no entanto, leva a negociações e alianças como premissas para realizar a democracia. $\mathrm{O}$ processo democrático torna-se viável, desconsiderada a via autoritária, ad limine, quando orientado por uma perspectiva centrista. O tratamento dos posicionamentos políticos pela via teórica do centro - centro-direita e centro-esquerda - permite, assim, contribuir para elucidar tanto a natureza como a efetividade da política. A convergência para o centro, concebido como híbrido político, observada nos resultados de nossa pesquisa, indica a existência de précondições para a realização da democracia, como prática fundada no discurso racional, dado seu distanciamento de antagonismos inconciliáveis.

\section{REFERÊNCIAS}

BOBBIO, N. Dicionário de Política. Unb: Brasília, 1997.

BOURDIEU, P. Ofício de sociólogo: metodologia da pesquisa na sociologia. Petrópolis: Vozes, 2004 .

DORTIER, J. F. Dicionário de Ciências Humanas. Rio de Janeiro: Martins Fontes, 2010.

GIDDENS, A. As consequências da modernidade. São Paulo: Unesp, 1991. HUTTON, W.; GIDDENS, A. No limite da racionalidade: convivendo com o capitalismo global. Rio de Janeiro: Record, 2004.

LATOUR, B. Jamais fomos modernos. Rio de Janeiro:34, 1994.

Argum., Vitória, v. 10, n. 2, p. 174-189, maio/ago. 2018. 
LATOUR, B. Reensablar lo social: una introducción a la teoria del actor-red. Buenos Aires: Manantial, 2008.

MARSHALL, T. H. Cidadania, classe social e status. Rio de Janeiro: Zahar, 1967.

PRZEWORSKI, A. Capitalismo e social-democracia. São Paulo: Companhia das Letras, 1995.

PUIG, S. M. Nicaragua: la consolidación de un régimen híbrido. Revista de Ciência Política, Santiago: Pontificia Universidad Católica de Chile, v. 33, n. 1, p. 269-286, 2013.

RODRIGUES, L. M. Partidos, ideologia e composição social: um estudo das bancadas partidárias na Câmara dos Deputados. São Paulo: Edusp, 2002.

TAROUCO, G. da S.; MADEIRA, R. M. Partidos, programas e o debate sobre esquerda e direita no Brasil. Revista de Sociologia e Política, Curitiba: UFPR, v. 21, n. 45, p. 149-165, 2013.

TRIBUNAL SUPERIOR ELEITORAL (Brasil). O tribunal da democracia. Brasília (DF), 2014. Disponível em: <http://www.tse.jus.br/imprensa/noticias-

tse/2014/Dezembro/plenario-do-tse-proclama-

resultado-definitivo-do-segundo-turno-da-eleicao-presidencial>. Acesso em: janeiro de 2018.

WEBER, M. Economia e sociedade. v. 1. Brasília: Unb, 2009.

Alysson HUBNER contribuição na pesquisa e elaboração do artigo

Cientista Político. Doutor em Sociologia. Mestrado em Sociologia Política. Graduação em Ciências Políticas e

Sociais (UNICS).

Joel PAESE contribuição elaboração do artigo

Professor Universitário. Doutor em Sociologia Política. Mestre em Sociologia. Graduação em Ciências Sociais (UNISINOS). 